\title{
ON THE HISTOPATHOLOGY OF CHONDRODERMATITIS NODULARIS HELICIS CHRONICA
}

\author{
BY \\ JAMES CALNAN AND BRUNO ROSSATTI \\ From the Department of Plastic Surgery, Churchill Hospital, Oxford
}

(RECEIVED FOR PUBLICATION JULY 4, 1958)

The histological features of chondrodermatitis have been well described in recent papers by Carol and van Haren (1941), Newcomer, Steffen, Sternberg, and Lichstenstein (1953), Shuman and Helwig (1954), and McConnell (1957). The epidermis shows acanthosis, with irregular broadening and deepening of the dermal papillae and hyperkeratosis with keratotic plugging of the follicles. The epithelium is often ulcerated, with fibrinous material in the base ; deep to this roundcelled infiltration extends down into the corium where there is a proliferation of fibrovascular tissue. The latter reaction may be so marked as to resemble a vascular hamartoma. The perichondrium may be thickened or be involved by the down growth of the vascular granulation tissue. The underlying cartilage, often normal, may show degenerative changes or even necrosis due to direct involvement in the ulcer.

Although the histopathology of this condition has been repeatedly studied, several features and symptoms draw attention to its similarity to the glomus tumour. Pain in the helix appeared to be promoted not only by pressure but also by alteration in the temperature of the part. Also a painful cutaneous nodule, in an area where there are arteriovenous anastomoses, is almost diagnostic of a glomus tumour. These points suggested a re-examination of the histological specimens of patients already treated, and a study of new cases by more suitable histological techniques.

In the past four years, 21 cases referred by dermatologists have been seen. Of these, 18 have

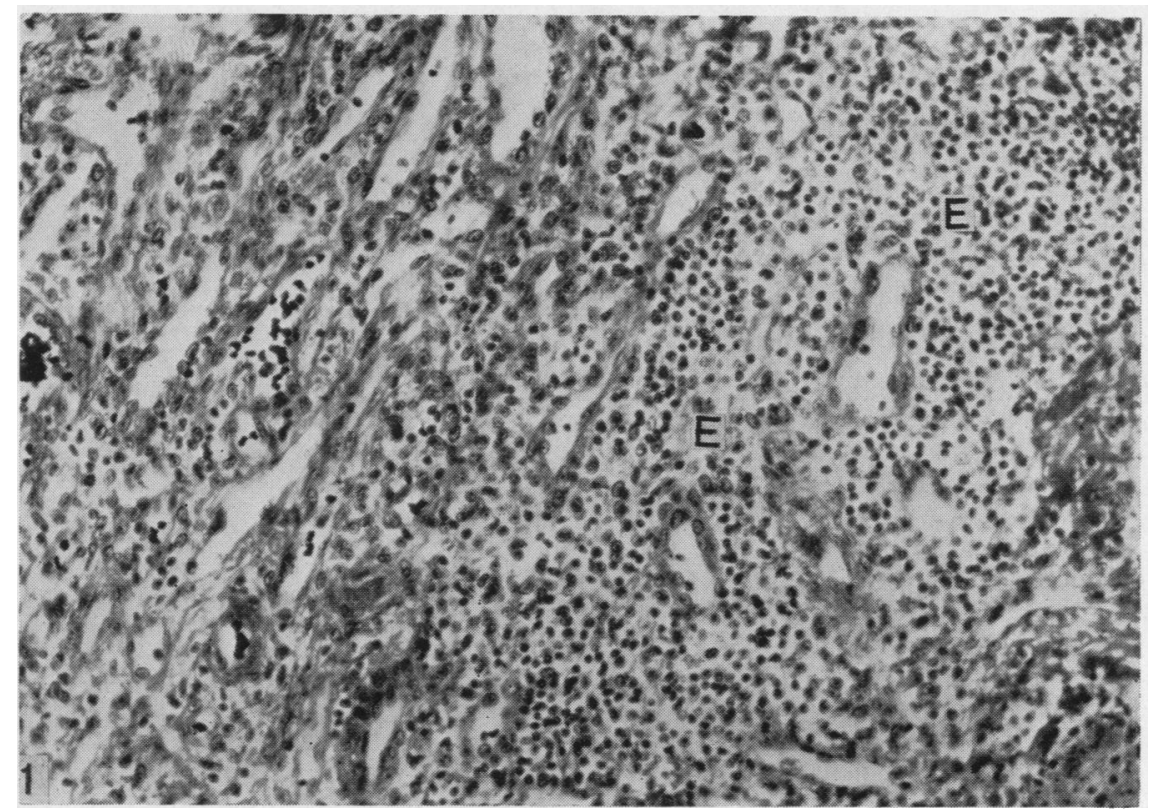

FIG. 1.-Papillary layer of the dermis in a case of chondrodermatitis helicis. Extensive infiltration of epithelioid cells (E). Mallory-Azan; $\times 220$. 

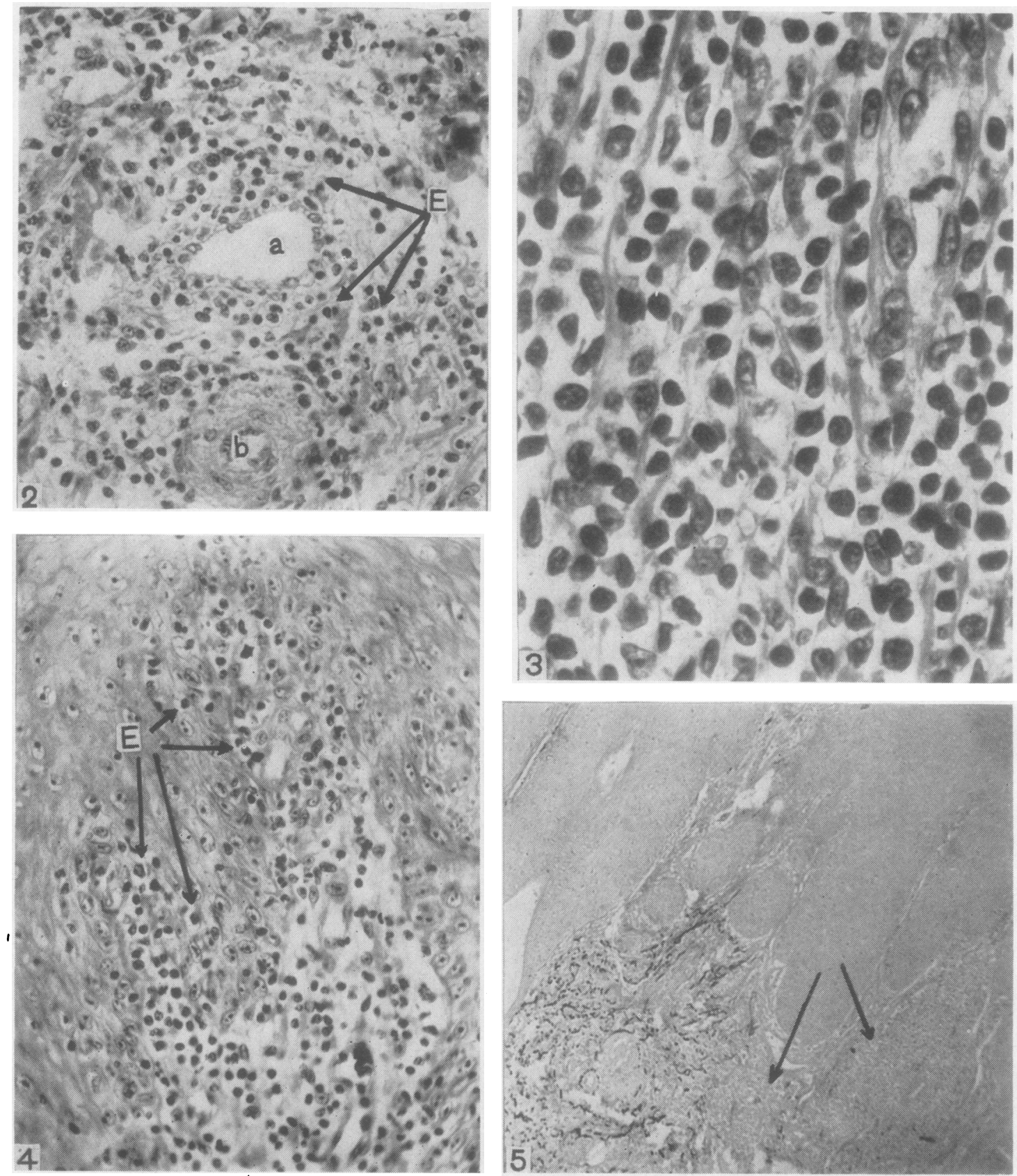

Fig. 2.-Artery (a) with epithelioid differentiation of the media probably intermediate portion of an arteriovenous anastomose). (b) Normal arteriole for comparison. Note the proliferation of epithelioid cells (E) in the surrounding tissue and the distinctive clear cytoplasm of these. Mallory-Azan; $\times 290$.

Fig. 3.-A clump of epithelioid cells: note the fine stroma. Mallory-Azan; $\times 80$ ).

Fig. 4.-Infiltration of epithelioid cells (E) in the deeper layers of the stratum Mulpigia. Mallory-Azan; $\times 290$.

FiG. 5. - The normal network of elastic fibres is absent in the aress of epithelioid cell proliferation (arrows). Weigert; $\times 50$. 
been treated, in one the lesion resolved spontaneously, one refused further treatment having had three lesions excised previously, and one has been retained for observation on the natural history of the complaint.

\section{Material and Methods}

The present study includes 21 cases, diagnosed as chondrodermatitis, of which four have been examined by serial section. Specimens were fixed in formol-saline, Susa, or alcohol. Paraffin sections $6 \mu$ thick were stained with Mallory-Azan, Masson, haematoxylin and eosin, Unna-Taenzer and Weigert for elastic tissue. The method of Cajal-De Castro for nerve fibres was also used.

\section{Personal Observations}

The accepted histological features were confirmed, but in three-quarters of the cases clear evidence was found of an unusual proliferation of epithelioid cells of the walls of arteriovenous anastomoses, a finding characteristic of glomus tumours of the type described by Masson (1924) in the finger tips.

The affected area is very rich in vessels with small lumina (Fig. 1), mainly arterioles, the walls of which are formed by stratified layers of epithelioid cells. It is often possible to ascertain that such proliferation initiated from the wall of these vessels and then flared out into the surrounding tissue (Fig. 2). There are also areas in which epithelioid cells have assumed the usual infiltrative appearance of a tumour ; they may be arranged in clumps or in palisade formation with a fine network of stromal tissue (Fig. 3). This proliferation mainly occupies the superficial layer of the dermis or the dermal papillae with little tendency to infiltrate the cartilage. Migration of epithelioid cells from the papillae into the superficial layers of the epidermis has also been observed (Fig. 4). In several cases accompanying inflammatory and degenerative changes were noted : round cells and localized areas of mucoid degeneration may be found scattered among the glomus tumour cells, mainly in the superficial layers. Such inflammatory infiltration may completely mask the presence of epithelioid cells and so lead to an incorrect conclusion.

Epithelioid cells are readily recognized in sections stained by the Mallory-Azan method. The normal network of elastic fibres in the dermis is absent in the zones occupied by solid clumps of epithelioid cells (Fig. 5). Nerve fibre stains did not show any unusual pattern in the innervation of the skin. The rate of proliferation of these cells does not appear to be very high, for mitoses are extremely rare. Ulceration of skin seems to be related to the lack of blood supply due to tumour infiltration in the underlying papillae, and hence degenerative changes in the epidermis and in the cartilage could be regarded as secondary.

\section{Discussion}

There is no doubt that the cellular proliferation observed in many cases of chondrodermatitis, reported here, has to be regarded as a typical proliferation of the specific cells present in the wall of arteriovenous anastomoses, which have been demonstrated in the human ear by Prichard and Daniel (1956). Their peculiar characteristics are readily recognized when suitable staining methods are employed. It follows that when epithelioid cells proliferate in this fashion, the lesion should be classified under the heading of "glomus tumour." It should not be inferred that all cases of chondrodermatitis are to be considered glomus tumours of the helix, but some cases can be associated with the presence of a small glomus tumour and the symptoms are likely to be due to the latter.

Cases of glomus tumour of the auricle have been recorded by Opitz (1954), Ratzenhofer (1941), Sannicandro (1936), and Ertl (1943). None of these had been previously classified as chondrodermatitis, most likely because of their size (which was larger than the usual nodule) or because of their different situation (neither on the helix margin nor the antihelix).

The only report in which the association of chondrodermatitis and glomus tumour is clearly demonstrated is that of Fernández and Monserrat (1931), who described one case in a man aged 38. These authors concluded that this case was one of glomus tumour and felt that all cases of chondrodermatitis should be so classified. Stout (1935) did not accept the diagnosis, while Freudenthal, Anderson, and Weber (1937) commented, "This case is apparently a chondrodermatitis nodularis helicis and not a glomus tumour," without any further explanation. The opinion of Fernández and Monserrat, however, is supported by photomicrographs which show a proliferation of epithelioid cells. Their interpretation was correct for that case, but we are unable to share their enthusiasm in advocating the classification of chondrodermatitis as glomus tumour on every occasion. Only certain of the cases examined, although a majority, exhibited evidence of proliferation of epithelioid cells for which the diagnosis of glomus tumour is justified. 


\section{Summary}

Twenty-one cases of chondrodermatitis nodularis helicis chronica are reviewed. In more than three-quarters of these cases there is evidence of extensive proliferation of epithelioid cells from the wall of arteriovenous anastomoses, and therefore such cases have to be considered as small glomus tumours of the helix.

\section{REFERENCES}

Carol, W. L. L., and Haren, H. B. van (1941). Dermatologica (Basel) 83, 353.

Ertl, E. (1943). Mschr. Ohrenheilk, 77, 15.
Fernández, A. A., and Monserrat, J. L. E. (1931). Sem. méd. (B Aires), 38 (2), 1693.

Freudenthal, W., Anderson, R. G., and Weber, F. Parkes (1937). Brit. J. Derm., 49, 151.

Masson, P. (1924). Lyon chir., 21, 257.

McConnell, E. M. (1957). J. clin. Path., 10, 46.

Newcomer, V. D., Steffen, C. G., Sternberg, T. H., and Lichtenstein, L. (1953). A.M.A. Arch. Derm. Syph., 68, 241.

Opitz, K. (1954). Zbl. Allg. Path. path. Anat., 92, 172.

Prichard, M. M. L., and Daniel, P. M. (1956). J. Anat. (Lond.), 90, 309.

Ratzenhofer, M. (1941). Zbl. Allg. Path. path. Anat., 77, 173.

Sannicandro, G. (1936). Dermosifilografo, 11, 424.

Shuman, R., and Helwiz, E. B. (1954). Aner. J. clin. Path., 24, 126.

Stout, A. P. (1935). Amer. J. Cancer, 2i, 255. 